\title{
IMPLANTAÇÃO DA UNED/ETFRN EM MOSSORÓ: A PRIMEIRA EXPANSÃO DA EDUCAÇÃO PROFISSIONAL FEDERAL NO RIO GRANDE DO NORTE
}

\author{
Karla da S. Queiroz; Francisco das Chagas S. Souza \\ Universidade Federal do Rio Grande do Norte; Instituto Federal de Educação, Ciência e Tecnologia do Rio Grande do \\ Norte \\ karlasqueiroz@gmail.com; chagas.souza@ifrn.edu.br \\ 10.15628/rbept.2017.6329
}

\section{RESUMO}

O artigo ora apresentado trata-se de parte de uma pesquisa de mestrado realizado no Programa de Pós-Graduação em Educação Profissional, do Instituto Federal de Educação, Ciência e Tecnologia do Rio Grande do Norte. Seu objetivo é analisar a implantação da Unidade de Ensino Descentralizada (UNED) da Escola Técnica Federal do Rio Grande do Norte, em Mossoró, no interior do Estado do Rio Grande do Norte, por meio do Programa de Expansão e Melhoria do Ensino Técnico (PROTEC). O estudo configura-se como uma pesquisa bibliográfica, documental e de campo, em que lançamos mão de uma variedade de fontes: revisão de literatura, documentos e entrevistas. Como resultados, destacamos que a criação dessa instituição de Educação Profissional é resultado de uma política de crescimento econômico voltado para a industrialização, a qual necessitava de mão-de-obra especializada. Já a criação da UNED em Mossoró se explica pelas condições favoráveis daquela cidade em termos econômicos. A instituição era vista como fator de desenvolvimento para o interior do Rio Grande do Norte.

Palavras-Chaves: Educação Profissional, PROTEC, História das Instituições Escolares.

\section{ABSTRACT}

The article presented it is a part of a master's research carried out in the PostGraduation Program in Professional Education, Federal Institute of Education, Science and Technology of Rio Grande do Norte. Its objective is to analyze the implementation of the Decentralized Education Unit (UNED) of the Federal Technical School of Rio Grande do Norte, in Mossoró, in the countryside of the State of Rio Grande do Norte, through the Program for Expansion and Improvement of the Technical Education (PROTEC). The study is a bibliographical, documentary and field research, in which we use a variety of sources: literature review, documents and interviews. As a result, we highlight that the creation of this institution of Professional Education is the result of a policy of economic growth focused on industrialization, which required specialized labor. In this sense the creation of the UNED in Mossoró is explained by the favorable conditions of the town in economic terms. The institution was seen as a development factor for the countryside of Rio Grande do Norte.

KEYWORDS: Professional Education, PROTEC, History of School Institutions. 


\section{INTRODUÇÃO}

A História da Educação Profissional no Brasil, na perspectiva da institucionalização de um sistema educacional em âmbito nacional, mostra-nos que o desenvolvimento de instituições que primam pelo ensino das profissões, apresentou, ao longo de todo o seu percurso, uma íntima aproximação com o projeto de crescimento econômico nacional que tem uma profunda relação com o desenvolvimento da indústria.

A exemplo da criação das Escolas de Aprendizes Artífices, em 23 de setembro de 1909, por meio do Decreto 7.566, do Presidente da República Nilo Peçanha, que objetivava atender a carência de mão-de-obra especializada para mercado de trabalho, o conjunto de leis e instituições elaboradas pelos governos posteriores preservaram o fomento da Educação Profissional enquanto instrumento a serviço do desenvolvimento econômico do país. Dessa forma, é possível afirmar que o avanço industrial acabou por tencionar a implementação de medidas no campo da educação formal.

Nessa direção, foi operacionalizada a primeira expansão da Educação Profissional, ocorrida nas duas décadas finais do século passado, proposta na presidência de José Sarney (1985-1990), por meio do lançamento do Programa de Expansão e Melhoria de Ensino Técnico (PROTEC), no bojo da execução do o I Plano Nacional de Desenvolvimento (PND) da Nova República.

O objetivo deste artigo é discutir a implantação da Unidade de Ensino Descentralizada (UNED) da Escola Técnica Federal do Rio Grande do Norte (ETFRN), em Mossoró, como uma consequência do PROTEC. Trata-se de um estudo proveniente de nossa pesquisa de mestrado em Educação Profissional, no Instituto Federal de Educação, Ciência e Tecnologia do Rio Grande do Norte. O estudo configura-se como uma pesquisa bibliográfica, documental e de campo, em que lançaremos mão de uma variedade de fontes: revisão de literatura, documentos oficiais e entrevistas abertas.

Em um primeiro momento, apresentamos o PROTEC como parte do panorama nacional da época, inserido nos documentos oficiais produzidos pelo governo federal. Em seguida, para compreendermos os caminhos trilhados para a instalação da UNED/Mossoró e as expectativas que essa escola trazia para o desenvolvimento local, discutiremos o cenário socioeconômico mossoroense nas décadas de 1980 e 1990.

\section{O PROTEC E A INTERIORIZAÇÃO DO ENSINO TÉCNICO}

Em pleno processo de redemocratização da política brasileira, após os 21 anos da Ditadura Militar, o presidente José Sarney lançou, em 6 de junho de 1986, por meio da Lei n 7.486, o I Plano Nacional de Desenvolvimento (PND), o qual, dentre outras coisas, trouxe inovações para o campo da Educação Profissional. Esse investimento se deu em função do interesse em implementar um projeto de governo pautado no crescimento econômico, com base num processo industrial que apresentava como questão central a introdução de novas tecnologias que proporcionassem maior competitividade no plano internacional e ampliação do mercado interno. O desafio que se colocava era o desenvolvimento consistente de tecnologia de ponta, para superar o atraso de anos de incipientes investimentos científicos e tecnológicos, comotambém a educação e formação de recursos humanos.

Para superar os anos de estagnação do desenvolvimento tecnológico, as estratégias apontadas no I PND indicavam a necessidade de estruturação de redes de criação tecnológica que integrassem centros de pesquisas, universidades e indústrias, com o objetivo de expandir e transferir os avanços alcançados para o setor de produção. 
Do mesmo modo, a formação de recursos humanos, outro elemento fundamental para o sucesso do projeto governamental desse período, também obteve atenção especial, de modo que recebeu destaque a questão educacional em seus vários níveis e modalidades de ensino e as linhas programáticas de cada um. No item 2.2 desse documento, denominado Programa Melhoria do Ensino de $2^{\circ} \mathrm{Grau}$, definiu-se que:

As escolas técnicas federais de $2^{\circ}$ grau - industriais e agrícolas receberão recursos necessários ao reforço e a ampliação de sua capacidade de atendimento, de tal forma que diversifiquem a oferta de habilitações, estendendo-as, tanto quanto possível ao setor de serviços modernos (BRASIL 1986).

Visando implementar os objetivos propostos para a área educacional, especialmente no que tange ao ensino de $2^{\circ}$ grau profissional, o governo Sarney publicou a Exposição de Motivos n 56, de 24 de fevereiro de 1986, no Diário Oficial da União em 26 de fevereiro de 1986, que trata da "implementação de um programa de expansão e melhoria do ensino de $2^{\circ}$ grau" (BRASIL, 1986b) e na Exposição de Motivos n 135, de 4 de julho de 1986, publicada no Diário Oficial da União, de 07 de julho de 1984, no qual elenca medidas no âmbito do Programa de Expansão e Melhoria do Ensino Técnico, a serem desenvolvidas em conjunto com o Ministério Extraordinário para Assuntos de Administração, com vistas à consecução dos recursos humanos necessários ao funcionamento das escolas" (BRASIL, 1986c).

Tais documento foram a base para o lançamento do Programa de Expansão e Melhoria do Ensino Técnico (PROTEC), oficializado em 04 de julho de 1986.Este programa previa a implantação de duzentas escolas técnicas industriais e agrotécnicas em todo o Brasil, dando prioridade às cidades dos interiores dos estados brasileiros, para atender às necessidades do processo de industrialização e possibilitar a formação de profissionais qualificados para o campo, norteados pela política de modernização e justiça social.

De acordo com os documentos oficiais, a implantação do PROTEC era justificada nas alegações de que estas escolas deveriam atender tanto às demandas provenientes da expansão e modernização da indústria, agricultura e serviços, como também à entrada da população jovem no mercado de trabalho.

Entretanto, a criação do PROTEC estava ligada a interesses mais políticos que técnicos e sociais, ficando explicito o critério clientelista em que foi edificado (CUNHA 2005; FRIGOTTO, FRANCO, MAGALHÃES, 2006). É relevante ressaltar que a orientação de distribuição dessas duzentas escolas evidencia esse clientelismo na medida em que se verifica que muitas dessas instituições foram instaladas em localidades com insuficiente ou inexistente desenvolvimento industrial como destacou Kirschner (1993). Ou seja, foram levados em consideração pedidos de diversos políticos que chegavam em grande quantidade ao Ministério da Educação (MEC).

Além de apresentar a proposta de expansão do ensino técnico como suporte em atenção ao mercado de trabalho, também estava delegado à essas escolas, o domínio efetivo da técnica e o aprimoramento dos processos tecnológicos, o que revela a concepção produtivista e tecnicista de educação implantada por meio do PROTEC.

A ideia produtivista aqui expressa se insere na perspectiva da centralidade no mercado, que nada mais é que o próprio sistema de produção capitalista. Como relata Frigotto, Franco e Magalhães (2006, p.140), "o grande e fundamental educador é o capital, disfarçado sob a categoria mercado de trabalho". 
Sendo o ensino técnico elaborado para satisfazer aos interesses do mercado de trabalho, em outras palavras, do próprio capital, o que estava em pauta não era a organização do sistema educacional para suprir as necessidades da sociedade enquanto coletivo humano, mas sim a organização e satisfação do sistema econômico, através da capacitação de recursos humanos, ou classe trabalhadora objetivando o aumento da produtividade e da maximização do lucro.

Já o caráter tecnicista empreendido ao PROTEC estava impresso na íntima associação do ensino técnico com o desenvolvimento. O programa era visto como "fator de primeira grandeza para o desenvolvimento nacional" e "instrumento fundamental à melhoria da produtividade nacional” (BRASIL 1986, p. 414). O ensino técnico deveria ser produtor de tecnologia para que o país pudesse progredir, o que supunha assim a necessidade de massificação, ampliação desse ensino.

Segundo Frigotto, Franco e Magalhães (2006), de fato havia uma demanda por formação técnica a ser resolvida, porém não sob os moldes do paradigma tayloristafordista de organização do trabalho e qualificação técnica inscritos no PROTEC. De acordo com este paradigma, o progresso da ciência e da tecnologia traziam como necessidade a generalizada qualificação da mão-de-obra, ao passo que possibilitaria a ampliação da oferta de emprego, aproximando ao pleno emprego, ou seja, gozando de direitos trabalhistas legalmente adquiridos.

O novo contexto neoliberal e de acumulação flexível que se evidenciava mundialmente, inclusive no Brasil, manifestava-se na educação, sob a exigência de uma qualificação não apenas técnica, mas que pudesse oferecer, como sinaliza Frigotto, Franco e Magalhães (2006, p. 145), "uma formação mais complexa, abstratas e polivalentes, para formar trabalhadores subordinados aos interesses do capital". Assim, estavam postas as novas condições para o retorno da velha conhecida Teoria do Capital Humano, agora tendo como mentores os organismos como o Banco Mundial, o Banco Interamericano de Desenvolvimento (BID), a Organização das Nações Unidas para a Educação, Ciência e Cultura (UNESCO), a Organização Internacional do Trabalho (OIT).

Para Frigotto (1986, p. 224), as instituições escolares se tornam instrumentos à serviço do capital:

Sua improdutividade, dentro das relações capitalistas de produção, torna-se produtiva. Na medida em que a escola é desqualificada para a classe dominada, para os filhos dos trabalhadores, ela cumpre, ao mesmo tempo, uma dupla função na reprodução das relações capitalistas de produção: justifica a situação de explorados e, ao impedir o acesso ao saber elaborado, limita a classe trabalhadora na sua luta contra o capital.

No plano da execução do PROTEC são identificadas duas modalidades de atuação que seriam executadas no ensino de $1^{\circ}$ e $2^{\circ}$ grau, que são: construção das escolas e instalação de equipamento pelo MEC. Na prática, o programa se materializou de maneira diferente da ideia veiculada oficialmente no programa. Não houve a implantação/construção de duzentas Escolas Técnicas Industriais e Agrícolas, mas, como denominou Cunha (2005), de fato seriam realizados duzentos convênios, beneficiando escolas já existentes e construção de novas estruturas. 0 primeiro ano de execução dedicado basicamente a recuperação das já existentes, denunciando também um caráter obreirista impresso no programa. 
Mais tarde, o MEC se viu obrigado a reconsiderar sua meta audaciosa e a formatação inicialmente planejada. Para tanto, criou, por meio da Portaria $N^{\circ} 67$, de 09 de fevereiro de 1987, um sistema de escolas técnicas no formato de Unidades de Ensino Descentralizadas (UNEDs), equivalente aos campi universitários, viabilizando assim a interiorização do ensino técnico.

\section{UNED MOSSORÓ: UMA ESCOLA PARA O PROGRESSO}

Mossoró, município localizado no oeste do Rio Grande do Norte, na década de 1980, apresentava as condições favoráveis à implantação de uma das UNEDs, visto que experimentava vertiginoso dinamismo econômico, crescimento urbano e aumento de oferta de empregos especializados, experimentando uma intensa expansão .

De acordo com os dados extraídos do Instituto Brasileiro de Geografia e Estatística (IBGE, 2016), a população mossoroense, que apresentava um número absoluto de 97.245 habitantes em 1970, teve um acréscimo de mais de $50 \%$ na avaliação da década seguinde, chegando a alcançar a marca de 145.981 habitantes, em 1980.

Ao passo que cresceu a população, a cidade também presenciou um aumentou em sua área habitada. Segundo relata Pinheiro (2007, p.173):

[...] no período entre 1975 e 1982, Mossoró passou por alterações radicais. [...] a cidade apresentava 32 loteamentos implantados, ou em fase de implantação, que se expandiam dando continuidade ao padrão de crescimento estabelecido na década de 1970, com o principal eixo de expansão no sentido sudeste-noroeste, ou seja, no sentido NatalFortaleza. No entanto, apesar do principal eixo de expansão ser no sentido sudeste-noroeste, a expansão urbana se deu para todos os lados.

Conforme mostraram os estudos de Rocha (2009) e Pinheiro (2007), tal expansão foi proporcionada pelo desenvolvimento de três importantes atividades econômicas: a indústria salineira, a indústria petrolífera e a fruticultura irrigada.

As atividades salineiras mossorenses, realizada até início da década de 1970 ainda de maneira bastante rudimentar, foram submetidas a intensa modernização em razão da grande quantidade do sal marinho demandado pela Indústria Química Nacional. Para satisfazer esta necessidade, as empresas salineiras empreenderam significativas transformações no modo de produzir esse mineral,desenvolvendo e setor e possibilitando uma produção mais rápida e de melhor qualidade.

A segunda atividade econômica de grande expressividade, a extração de petróleo, desenvolveu-se a partir do final da década de 1970, com a descoberta de petróleo em solo, com relevante potencial extrativo. A partir de então, o segmento petrolífero começou a se estabelecer na cidade com a instalação de um escritório da Petrobras, iniciando as atividades de exploração de petróleo e gás natural, que viria a representar participação preponderante nas arrecadações estadual e municipal.

A relevância da exploração de petróleo em Mossoró pode ser medida pelo fato de, à época, essa cidade ter reunido o maior número de poços em produção do Rio Grande do Norte. A descoberta do Poço do Canto do Amaro transformou a Bacia Potiguar na região responsável pela maior produção de petróleo em área terrestre do país. 
Para compor a tríade da economia mossoroense, a fruticultura irrigada veio agregar relevante contribuição para o desenvolvimento da cidade, tendo sido implementada especialmente no meio rural. Essa economia ganhou corpo a partir da década de 1970 quando ações governamentais centravam esforços para o desenvolver as regiões que sofrem os efeitos da seca. Neste sentido foram priorizando processos de agricultura irrigada, que passaram a ser alvo de importantes investimentos propiciando a criação de Polos de Fruticultura.

Estes por sua vez adquiriram dinamismo com a inserção de novos mecanismos de exploração da produção agrícola, com forte presença de tecnologia, capital e informação. Tal feito foi considerado um dos processos de modernização mais intensos do Rio Grande do Norte e do Brasil, concedendo a Mossoró o título de produtor de frutas tropicais reconhecido internacionalmente.

Juntos, esses três setores econômicos alteraram de forma significativa a paisagem dessa cidade, que apresentou um acentuado crescimento urbano e populacional, tornando Mossoró uma possibilidade viável para a efetivação do PROTEC no interior do Rio Grande do Norte.

Os primeiros achados relativos às ações realizadas na perspectiva de apontar Mossoró como cidade atrativa para a implantação da UNED partiram do segmento político. De acordo com documentos arquivados na Câmara Municipal de Mossoró, em 20 de março de 1986, o vereador Francisco Borges solicitou àquela casa, por meio do requerimento 54/86, o encaminhamento de um ofício ao então Ministro da Educação, Jorge Bornhausen, solicitando a inclusão de Mossoró na lista dos municípios a serem beneficiados com a implantação de uma unidade da ETFRN. No documento, mas também em entrevista que nos concedeu, o vereador argumentou que a cidade apresentava liderança na região e disponibilidade de infraestrutura. Segundo o texto do documento:

Sendo do pensamento prioritário do Presidente Sarney, criar novas Escolas Técnicas Federais nos Estados, venho solicitar dos meus pares o apoio para nossa cidade, ser beneficiada com essa proposta presidencial, uma vez que Mossoró, além de cidade líder da região, dispõe de infraestrutura que se coaduna com o referido projeto.

O ex-vereador buscou também o apoio de outros políticos da estrutura parlamentar do Rio Grande do Norte: foram expedidos correspondência oficiais solicitando colaboração de deputados federais e senadores. Tantas intervenções políticas coadunam com a argumentação de Frigotto, Franco e Magalhães (2006) e Cunha (2005) de que a escolha das cidades que iriam sediar essas UNEDs, criadas por meio do PROTEC, priorizariam interesses clientelistas, embora Mossoró atendesse aos critérios de cidade com potencial econômico, expansão e modernização da indústria, agricultura e serviços, conforme orientação da documentação oficial de lançamento do Programa.

No plano institucional, o primeiro documento encontrado, acerca de discussões sobre a interiorização das Escolas Técnicas Federais (ETFs), aparece na Agenda ETFRN, de 23 de maio de 1986. Na agenda há o registro de que, na realização da XIV Reunião de Diretores das Escolas Técnicas Federais (REDITEC), estava em pauta a indicação de sugestões de criação de núcleos avançados. Ainda segundo esse documento, o MEC, realizaria, por meio de uma Comissão de Técnicos, um levantamento das condições físicas, potencial de alunos e demanda, em todos os municípios do país, com o objetivo de mapear os possíveis locais para instalação de unidade de ensino profissionalizante (ETFRN, 1986a). 
A partir das Agendas da ETFRN e de entrevistas que realizamos com gestores dessa instituição (dois ex-diretores gerais da ETFRN e um da UNED/Mossoró), além de pesquisas nas matérias da imprensa de Mossoró, conseguimos levantar informações importantes de como se deram os primeiros passos no processo de implantação da UNED Mossoró.

Definida a cidade de Mossoró, para sediar uma das UNEDs no Estado (outra seria na cidade de Currais Novos, mas não veio a se efetivar naquele momento por questões burocráticas), entra em cena, mais uma vez, o protagonismo da política mossoroense. O prefeito de Mossoró, Jerônimo Dix-huit Rosado, pleiteou junto à Escola Superior de Agricultura de Mossoró (ESAM), a cessão de parte de suas terras para construção da UNED. A solicitação foi atendida e o terreno foi cedido em termos de comodato à ETFRN, que passou a dispor de um lote com a dimensão de $97.200 \mathrm{~m}^{2}$ em Mossoró para o desenvolvimento da obra. O processo de tramitação da cessão data de agosto de 1986 (ETFRN, 1986a), sendo finalizada sua oficialização em 20 de março de 1987. Conforme determinação do Ministério da Educação, a construção deveria estar concluída até março de 1987.

O terreno estava situado "ao lado da rodovia que interliga os municípios de Mossoró e Areia Branca, servido por redes de energia elétrica e telefonia, água potável e telex, além de serviços urbanos de correio, limpeza e iluminação públicas, posto de saúde, posto policial e parada de ônibus" (ETFRN, 1986b).

É possível perceber que naquele momento havia um empenho do governo federal na efetivação do PROTEC. De acordo com a Agenda n 62, de 17 de setembro de 1986 (ETFRN, 1986c), em reunião realizada pelo Conselho de Diretores das Escolas Técnicas Federais (CONDITEC), foi informado, por intermédio da SADESE, que estavam disponibilizados, para a implantação das UNEDs, em todo o país, cerca de 467 milhões de cruzados (moeda brasileira à época), que deveriam ser aplicados ainda naquele semestre. Para a ETFRN, as primeiras parcelas do recurso totalizaram um valor de $\mathrm{Cz} \$ \mathbf{8 . 0 0 0 . 0 0 0 , 0 0}$ (oito milhões de cruzados) (ETFRN, 1986e).

Além da liberação dos recursos, a Agenda nº 63 (ETFRN, 1986d) destaca que o Governo Federal publicou,noDiário Oficial daUnião, umedital de concorrênciapública sob responsabilidade do CEDATE, para seleção de empresas para a construção de projetos arquitetônicos, de engenharia e de aquisição e instalação de equipamentos. Outra ação importante realizada pelo governo foi o Seminário de Orientação às Empresas de Consultoria, ocorrido em Brasília, para criação de projetos de arquitetura e engenharia para as novas escolas, promovendo diversas reuniões para discussão e detalhamento dos projetos e palestras sobre o PROTEC.

No Rio Grande do Norte, a ENGEVIX Engenharia S/A, empresa vencedora da concorrência pública nacional para construção dos projetos de arquitetura e engenharia, subcontratou a firma Arquitetos e Associados para a realização do trabalho que seria posteriormente apreciado e aprovado pelo MEC.

Finalizada essa etapa, iniciaram-se as discussões acerca do processo licitatório para a construção das UNEDs. Considerando-se que esse processo preparatório se estendeu até o final do segundo semestre de 1987, é possível perceber que já havia sinais de atraso no desenvolvimento do processo de implantação das Unidades no Rio Grande do Norte, haja vista a previsão do MEC para o funcionamento destas em março de 1987.

Dessa forma, um novo prazo para a conclusão da UNED em Mossoró foi definido: novembro de 1988. Porém, este também não foi cumprido, já que o edital de concorrência pública nacional para construção da escola só foi lançado no Diário Oficial da União, de 10 de novembro de 1989 (ETFRN, 1989). 
Vale destacar que nesse momento, o PROTEC enfrentava dificuldade em sua execução. Na realização do II Seminário de Avaliação Pedagógica/Administrativa das ETFRNs, CEFETs e Agrotécnicas, emBento Gonçalves-RS,oCONDITEC produziutrês documentos paraencaminhamento ao MEC, dois dos quais estavam relacionados ao desenvolvimento do programa: o primeiro tratava da discussão sobre os recursos financeiros e questionava a divisão orçamentária ao mesmo tempo em fazia, dentre outras reivindicações, a de alocação de recursos para a implantação das UNEDs; o segundo documento relatava os prejuízos, tanto para o ensino técnico quanto para a viabilidade da implementação do PROTEC, provenientes dos Decretos nº 95.682 e n 95.683, ambos de 28 de janeiro de 1988, que proibiam a contratação de servidores, docentes e técnicos administrativos (ETFRN, 1988a).

Apesar da limitação orçamentária, a ETFRN recebeu, ainda no primeiro semestre de 1988, um montante de recursos no valor de Cz\$ 46.000.000,00 (quarenta e seis milhões de cruzados) para serem investidos na construção das UNEDs, recurso originário de convênio assinado com a SESG/ MEC, ainda no exercício do ano anterior (ETFRN, 1988b).

Por meio das ações desenvolvidas pela ETFRN e do apoio político de vários representantes da bancada parlamentar norte-rio-grandense, estavam desenhados os contornos para enfim ser iniciada, em 12 de janeiro de 1990, a construção da UNED em Mossoró, cuja obra foi executada pelo Construtora Marialva S/A, de Sete Lagoas-MG. Em carta de apresentação da proposta para concorrência pública, a empresa informou que a obra estava orçada no valor de NCz\$79.800.000,00 (setenta e nove milhões e oitocentos mil cruzados novos), com prazo de execução dos serviços em cento e oitenta dias (MARIALVA, 1989). Entretanto, esse prazo também não foi atendido.

Conforme relatou o Professor Francisco das Chagas de Mariz Fernandes, sucessor da Professora Luzia Vieira de França na direção da ETFRN, ao iniciar a sua gestão, em 1991, as obras da UNED de Mossoró estavam praticamente paralisadas devido a questões de ordem financeira do Governo Federal e ao fato de o PROTEC ter perdido o caráter prioritário no governo do presidente Fernando Collor de Melo (1990-1992).

O relato de Professor Mariz nos revela fatos importantes sobre esse período. Segundo ele, a manutenção da construção, apesar da restrita liberação de verbas, foi possível em função das renegociações promovidas pelo próprio MEC, da influência política do deputado federal mossoroense Laíre Rosado e das cobranças por parte do empresariado local. Entretanto, a retomada da construção com mais vigor só foi possível com a implantação do Centro Integrado de Atenção à Criança e ao Adolescente (CAIC), estrutura física que atenderia ao desenvolvimento do Programa Nacional de Atenção Integral à Criança e ao Adolescente (PRONAICA) . Foi a partir da concepção desse programa e dos recursos dispensados para a construção do CAIC que a conclusão da UNED em Mossoró encontrou viabilidade.

Durante o período da construção, que se estendeu por quase cinco anos, a ETFRN apresentou uma intensa aproximação com a comunidade mossoroense. De acordo com Professor Mariz, foram realizadas diversas visitas a Mossoró, objetivando definições importantes para o funcionamento da instituição.

A discussão para a escolha dos cursos a serem oferecidos era um tema central, pois era a partir dessa determinação que outras decisões seriam tomadas, como é o caso da compra de equipamentos, da construção de laboratórios e da composição de corpo docente. Para tanto, foram realizadas duas reuniões abertas ao público, no auditório já construído da UNED, das quais participaram lideranças políticas, empresários locais e representantes das associações do comércio salineiro e da construção civil. Segundo o Professor Mariz, em entrevista já mencionada, tais reuniões para a escolha dos cursos tinham como referencial os polos de desenvolvimento da região. 
Dessa forma, atendendo às necessidades do desenvolvimento econômico da cidade, foram definidos os cursos de Construção Civil, para responder à demanda apresentada pelo vertiginoso crescimento urbano, e de Eletromecânica, para satisfazer aos anseios do setor industrial. Definidos os cursos, o próximo passo era aguardar a entrega definitiva das instalações da UNED.

Na iminência da inauguração da escola, momento amplamente divulgado pela imprensa escrita local, o sentimento era de que aquele empreendimento educacional proporcionaria um ensino profissionalizante de boa qualidade, ensino este que se encontrava "praticamente extinto na cidade", de acordo com o jornal Gazeta do Oeste, de 02 de dezembro de 1995 (ETFRN..., 1994).

Em 29 de dezembro de 1994, no apagar das luzes do governo Itamar Franco (1992-1995), foi enfim realizada a cerimônia de inauguração da UNED/ETFRN em Mossoró. As fotografias dessa solenidade, arquivadas na biblioteca do Campus Mossoró, registraram a presença de várias autoridades: o Ministro da Educação, Murílio Avellar Hingel; o Diretor Geral da ETFRN, Francisco das Chagas de Mariz Fernandes; o Diretor da ETFPB, Bráulio Pereira Lins; o Prefeito de Mossoró, Jerônimo Dix-Huit Rosado Maia; o Secretário de Educação do Rio Grande do Norte, Marcos Guerra; o Diretor da ESAM, Joaquim Amaro Filho; representantes da bancada parlamentar Laíre Rosado e Sandra Rosado, além do público em geral.

Havia muitas expectativas na sociedade mossoroense em função da qualidade do ensino que seria desenvolvido na ETFRN. Suas instalações causavam impacto por suas modernidade e infraestrutura. A imprensa local destacava a imponência da instituição: uma área construída de 7.522 metros quadrados, com quatorze salas de aulas teóricas, duas salas de desenho, uma biblioteca com 200 metros quadrados, um auditório com capacidade para 150 pessoas sentadas, vinte salas administrativas, dois alojamentos e vestiários (masculino e feminino), refeitório e lanchonete, gabinete médico-odontológico, enfermaria, dez baterias de sanitários, uma quadra de esportes descoberta, estacionamento e dezesseis laboratórios (INSTALAÇÕES..., 1994).

Inaugurada a UNED, era o momento de estabelecer as condições para o seu funcionamento. Para tanto, foram convocados os servidores e lançado edital de inscrições para a seleção de alunos, com duzentas vagas para o curso de Eletromecânica. 0 curso teria duração de quatro anos, sendo, nos três primeiros, ministradas as disciplinas de cunho científico e tecnológico e, no último ano, era ofertada a escolha por uma habilitação em Eletrotécnica ou Mecânica. Segundo o Jornal Gazeta do Oeste, de 07 de fevereiro de 1995, no penúltimo dia de inscrições, já havia quinhentos e oitenta candidatos inscritos, mas a perspectiva era de que esse número chegasse a mais de oitocentos. Isso reafirma as expectativas da população de que a escola seria a esperança de oferta de ensino público de qualidade e atuaria como elemento de transformação e desenvolvimento (MAIS..., 1995).

A respeito da oferta dos cursos, em entrevista concedida ao jornal Gazeta do Oeste, em 08 de janeiro de 1995, o Professor Nivaldo, já diretor da UNED/ETFRN, revela que, a princípio, havia uma decisão institucional para a oferta dos cursos de Eletromecânica e Química Industrial. Contudo, essa proposta não se concretizou, em função da escassez de recursos do Governo Federal, inviabilizando a estruturação da UNED para atuar em duas áreas do conhecimento. Dessa forma, foi possível apenas a implantação do curso de Eletromecânica, situação que seria atenuada com a oferta de cursos de extensão, especialmente na área de informática. Um ano mais tarde, teve início o curso de Construção Civil (CONVERSANDO..., 1995). O curso de Química Industrial, apesar da relevância da economia salineira para a cidade, nunca foi implantado. 
O destaque dado pelo diretor da UNED quanto à escassez de recursos chama a atenção. Por isso, na oportunidade em que o entrevistei, convidei o Professor Nivaldo para falar a respeito desse assunto. Ele comentou que:

A escola começou de uma maneira muito precária, porque ela não tinha orçamento. Uma escola daquela começou, me parece, com duzentos alunos, eram quatro turmas e não tinha orçamento. Então, a escola vivia com a sobra do orçamento do CEFET [da ETFRN] aqui de Natal. A ideia era essa mesma, o orçamento era o dessa escola. Então o diretor daqui fazia todas as economias possíveis para destinar algum recurso para Mossoró. Então era assim que Mossoró vivia, com a sobra do orçamento da Escola Técnica.

As atividades letivas da UNED tiveram início com a aula magna, realizada em 13 de março de 1995, proferida pela Professora Luzia Vieira de França, ex-diretora da ETFRN, abrindo, assim, o que foi intitulada pelo Jornal Gazeta do Oeste de a "era do ensino tecnológico de $2^{\circ}$ grau” em Mossoró (MOSSORÓ..., 1995).

\section{CONSIDERAÇÕES FINAIS}

A implantação da UNED Mossoró foi gestada em meio a um projeto político de desenvolvimento econômico nacional, com base no processo de industrialização e que encontrou terreno fértil na conjuntura local de Mossoró, em virtude do dinamismo econômico proporcionado pelo desenvolvimento das atividades econômicas salineira, petrolífera e de fruticultura irrigada, que impactou numa expansão urbana e populacional na cidade.

Dessa maneira a economia local não apenas foi responsável por oferecer as condições necessárias para que Mossoró apresentasse as condições favoráveis para a seleção das cidades sedes das UNED como também foram preponderantes para a tomada de decisões importantes da instituição, como foi o caso da escolha dos cursos que a instituição passaria a oferecer.

Também é importante considerar que para além dos esforços institucionais para tornar a UNED Mossoró uma realidade possível, se fizeram presentes as contribuições de diversos atores da política local e estadual para que o projeto de interiorização resistisse a ação do tempo e dos processos de descontinuidades característicos das políticas de governo de âmbito federal.

Contudo, é relevante destacar que esta escola criada em nome do progresso gerou grandes expectativas não apenas por oferecer ensino técnico para satisfazer uma demanda proveniente do desenvolvimento industrial, mas também encontrava considerável respaldo na sociedade mossorense por ser considerada uma instituição escolar de qualidade reconhecida. 


\section{REFERÊNCIAS}

BRASIL. Lei nº. 7.486, de 6 de junho de 1986. Aprova as diretrizes do Primeiro Plano Nacional de Desenvolvimento (PND) da Nova República, para o período de 1986 a 1989. Brasília: Diário Oficial da União, seção I, p. 8473, 1986a. Disponível em: <http://www.planalto. gov.br/ccivil_03/leis/1980-1988/L7486.htm>. Acesso em: 15 ago. 2014.

Exposição de Motivos n 56, de 24 de fevereiro de 1986. Implementação de um Programa de expansão e melhoria do ensino de $2^{\circ} \mathrm{grau}$, nos termos da presente Exposição de Motivos. Brasília: Diário Oficial da União, seção I, p. 2976, 1986b. Disponível em: <http:// www.jusbrasil.com.br/diarios/3218019/dou-secao-1-26-02-1986-pg-4/pdfView> Acesso em: 23 set. 2014.

Exposição de Motivos no 135, de 4 de julho de 1986. Elenco de medidas no âmbito do Programa de Expansão e Melhoria do Ensino Técnico, a serem desenvolvidas em conjunto com o Ministério Extraordinário para Assuntos de Administração, com vistas à consecução dos recursos humanos necessários ao funcionamento das escolas, nos termos da presente Exposição de Motivos. Brasília: Diário Oficial da União, seção II, p. 3458, 1986c. Disponível em: <http://www.jusbrasil.com.br/diarios/3529371/dou-secao-2-07-071986-pg-2/pdfView> Acesso em: 23 set. 2014.

Biblioteca da Presidência da República. Lançamento do Programa de Expansão e Melhoria do Ensino Técnico [Discurso do Presidente José Sarney]. Brasília: Biblioteca Presidência da República, 1986d. Disponível em: <http://www.biblioteca.presidencia.gov. br/ex-presidentes/josesarney/discursos/1986/79.pdf/at_download/file> Acesso em: 19 set. 2014.

CONVERSANDO com... Nivaldo Ferreira da Silva. Gazeta do Oeste, Mossoró-RN, 8 jan. 1995.

CUNHA, L. A. O ensino profissional na irradiação do industrialismo. São Paulo: UNESP, Brasília: FLACSO, 2005. 1986a.

ESCOLA TÉCNICA FEDERAL DO RIO GRANDE DO NORTE. Agenda, Natal, n. 25, 23 mai.

Agenda, Natal, n. 46, 13 ago. 1986b.

Agenda, Natal, n. 62, 17 set. 1986 c.

Agenda, Natal, n. 63, 22 set. 1986d.

Agenda, Natal, n. 74, 7 nov. 1986 e. 
Agenda, Natal, n. 165, 2 mar. 1988a.

Agenda, Natal, n. 170, 22 mar. 1988b.

Agenda, Natal, n. 237, 16 nov. 1989.

ETFRN pode ser inaugurada este mês. Gazeta do Oeste, Mossoró, RN, 2 dez.1994.

FRIGOTTO, G. A produtividade da escola improdutiva. 2 ed.São Paulo: Cortez, 1986.

FRIGOTTO, Galdêncio; FRANCO, Maria Aparecida Ciavatta; MAGALHÃES, Ana Lúcia (2006). Programa de Melhoria e Expansão do Ensino Técnico: expressão de um conflito de concepções de educação tecnológica. In FRIGOTTO, Gaudêncio; FRANCO, Maria Ciavatta. (Org.) A formação do cidadão produtivo: a cultura de mercado no ensino médio técnico. Brasília: INEP, 2006. p. 139-149

IBGE. População. 2013. Disponível em: <http://seriesestatisticas.ibge.gov.br/series. aspx?vcodigo=CD77>. Acesso em: 20 jan. 2016.

INSTALAÇÕES da ETFRN são um verdadeiro complexo estudantil. Gazeta do Oeste, Mossoró, RN, 30 dez.1994.

KIRSCHNER, Tereza Cristina. Modernização tecnológica e formação técnicoprofissional no Brasil: impasses e desafio. Brasília: IPEA,1993

MAIS de 500 se inscrevem na ETFRN; cadastramento se encerra neste dia. Gazeta do Oeste, Mossoró; 7 fev. 1995.

MARIALVA Construtora LTDA, [Carta] 08 dez. 1989, Sete Lagoas [para] Comissão de Licitação, ETFRN. 4f. Carta de apresentação de proposta.

MOSSORÓ passa a contar com sua unidade da ETFRN. Gazeta do Oeste, Mossoró, RN, 14 mar. 1995.

PINHEIRO, Karisa Lorena Carmo Barbosa. O processo de urbanização da cidade de Mossoró: histórico da expansão urbana da cidade de Mossoró desde 1.772 até os dias atuais. Mossoró: CEFET, 2007.

ROCHA, Aristotelina Perreira Barreto. A expansão urbana de Mossoró: período de 1980 a 2004. 2009. 